\title{
Magnitud de la Violencia Familiar y Aplicación de la Ley de Protección Frente a la Violencia Familiar por parte de las Instituciones Involucradas en la Provincia de Tacna en el Año 2008
}

RESPONSABLE: Abog. Escarleth Laura Escalante

RESUMEN. La investigación tiene como propósito establecer la magnitud de la violencia familiar (el perfil de la víctima y del victimario en cuanto a edad, sexo, situación económica y las características familiares que rodean tanto a la víctima como al victimario), y la aplicación de la ley de protección frente a la violencia familiar por parte de las instituciones involucradas (Juzgados de Familia). El objeto de estudio son expedientes de violencia familiar tramitados en los Juzgados de Familia de Tacna, durante el periodo 2007-2008. Se ha concluido que el perfil de la víctima, presenta como características principales que la mayoría son de sexo femenino, de edades entre los 26 a 39 años de edad, se dedican a labores de casa. Respecto al perfil del victimario, mayormente son de sexo masculino, con edades entre 26 a 39 años, sin trabajar. Entre las características familiares más importantes, se ha concluido que en la mayoría de los casos la víctima y el victimario son convivientes y comparten el mismo domicilio.
MIEMBRO: Abog. Rodolfo De Amat Quiroz

ABSTRACT The main research aims to establish the extent of family violence (the profile of the victim and the victimizer in age, sex, economic status, and family characteristics which attach to the victim and the perpetrator) and the application of protection law against domestic violence by the institutions involved (Family Court). The object of study, were the family violence cases processed in the Tacna family courts during the period $2007-2008$. It is concluded that the profile of the victim, presents as main characteristics the majority are female, have ages between 26 to 39 years old, are engaged in housework. Regarding the profile of the perpetrator, are mostly male, ages 26 to 39, without occupation. Among the most important family characteristics, it was concluded that in most cases the victim and the victimizer are living together and also share the same address.
INTRODUCCIÓN. La perspectiva sobre la violencia familiar ha pasado de ser vista como un problema privado a ser tomada como un asunto de interés público. $\mathrm{Si}$ bien este cambio formal es valioso, ha ofrecido cambios insuficientes en la práctica. Las denunciantes por violencia familiar no son debidamente satisfechas en su pretensión jurídica. Otros intereses y bienes jurídicos prevalecen sobre las vulneraciones motivo de su reclamo. La mayoria del personal policial aplica criterios indebidos para decidir si reciben la denuncia o no. Esta falta de interés refleja la falta de percepción de la violencia familiar como atentado contra los derechos humanos.

Las formas de abuso más frecuentes son las siguientes: a)Abuso Físico (la patea, golpea, cachetea, quema, sacude); b) Abuso Psicológico (la critica constantemente, la insulta, la aísla de la familia, amigos o compañeros de trabajo; c) Abuso Económico (no le permite trabajar o estudiar, le prohíbe el acceso a cuentas de banco); d) Abuso Sexual (la fuerza a tener relaciones sexuales o a participar en actividades sexuales que le desagradan).

Basandonos en lo expuesto, nos planteamos la siguiente interrogante: ¿Cuál es la magnitud de la violencia familiar (forma de inicio, conclusión, tipo de violencia familiar más frecuente, el perfil que presenta la víctima y el victimario en los casos de violencia familiar, las características familiares) y la aplicación de la ley de protección frente a la violencia familiar por parte de las instituciones involucradas en la provincia de Tacna (Juzgados de Familia) en el año 2008?

\section{MATERIALY MÉTODOS}

Ámbito de estudio:

El estudio se realizó en los Juzgados de Familia, del distrito de Tacna, en el año 2007-2008. La unidad de análisis fueron los expedientes sobre violencia familiar tramitados en los Juzgados de Familia durante el periodo señalado.

Población y muestra:

Población:

La población de estudio estuvo constituida por 140 expedientes de violencia familiar tramitados en los dos Juzgados de Familia de Tacna.

Muestra:

La muestra fue de 46 expedientes, a un nivel de confianza del $95 \%$ y un margen de error del 5\% y considerando un $\mathrm{P}=0,5$ y $\mathrm{q}=0,5$ como probabilidad de éxito y probabilidad de error, que hacen un total de $\mathrm{n}=$ 45 expedientes. 


\section{RESULTADOS Y DISCUSIÓN}

\section{Respecto al Perfil de la Víctima:}

Los hallazgos exidencian que las principales características son:

Juzgados de Familia Tacna: Estado Civil de la Victima, Año 2007-2008

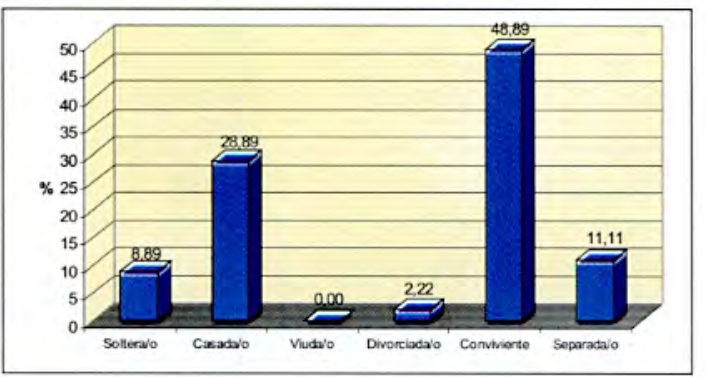

Respecto al estado civil se ha determinado que el $48,89 \%$ son convivientes y un $28,89 \%$ son casados, existiendo una menor proporción respecto a los solteros y separados $8,89 \%$ y $11,11 \%$ respectivamente.

Juzgados de Familia Tacna: Sexo de la Victima, Año 20072008

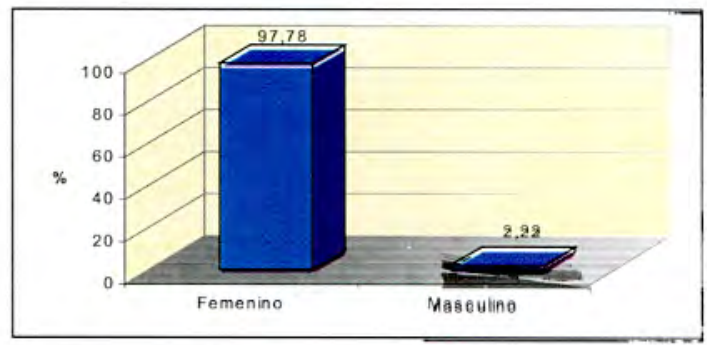

Del gráfico se tiene que el $98,78 \%$ de las víctimas son mujeres y $2,22 \%$ son varones.

Juzgados de Familia Tacna: Grado de Instrucción de la Victima, Año 2007-2008

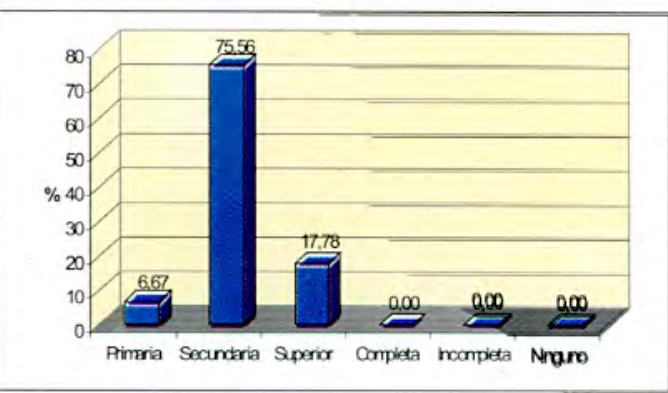

Respecto al grado de instrucción se ha determinado que el 75,56\% tiene educación secundaria, mientras que el $17,78 \%$ tiene estudios superiores, y solo el 6,67 por ciento tiene educación primaria, esto en cuanto se trata de víctimas.
Juzgados de Familia Tacna: Oficio o Profesión de la Victima, Año 2007-2008

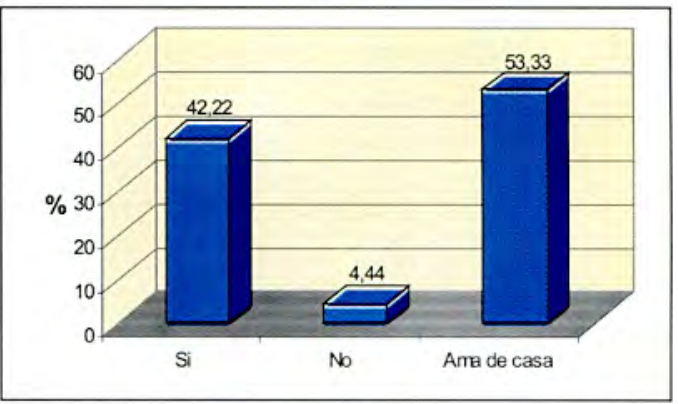

Respecto al oficio o profesión de la víctima, el $42,22 \%$ responde que sí tiene un oficio u profesión, el 4,44\% responde negativamente; y un 53,33 manifiesta ser ama de casa.

\section{En Relación al Perfil del Victimario}

Los hallazgos evidencian que las principales características son:

Juzgados de Familia Tacna : Estado Civil del Victimario, Año $2007=2008$

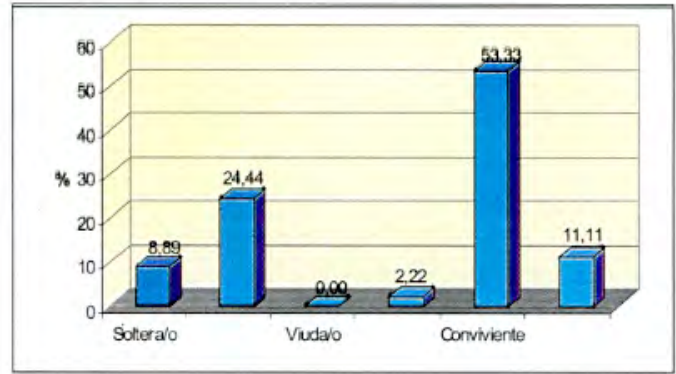

Respecto al estado civil del victimario, el 53,33\% son convivientes, mientras que un $24,44 \%$ son casados, el $11,11 \%$ son separados; un $8,89 \%$ solteros, y $2,22 \%$ son divorciados.

Juzgados de Familia Tacna: Sexo del Victimario , Año $2007-$ 2008

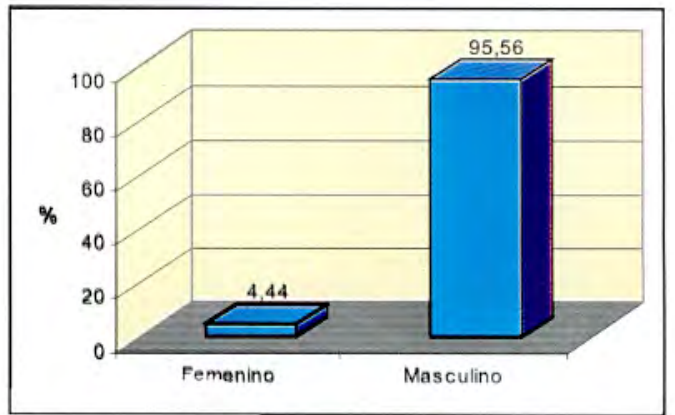

Respecto al sexo del victimario, un $95,56 \%$ son varones, mientras que sólo un $4,4 \%$ corresponde al sexo femenino. 
Juzgados de Familia Tacna : Edad del Victimario, Año $2007-$ 2008

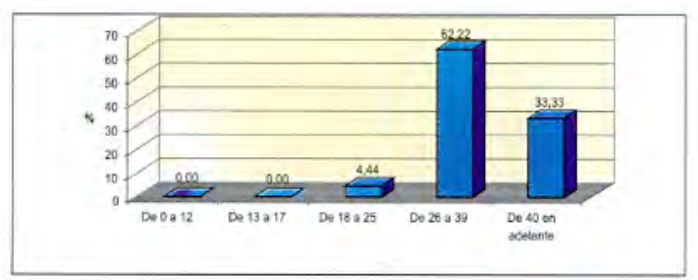

El $62,22 \%$ de los victimarios presentan edades comprendidas entre 26 a 39 años, un $33,33 \%$ son mayores de 40 años y solo un $4,44 \%$ entre los 18 y 25 años de edad

Juzgados de Familia Tacna: Grado de Instrucción del Victimario, Año 2007-2008

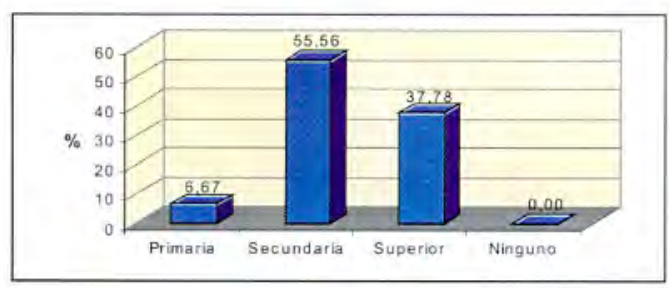

Se ha determinado que el $55,56 \%$ de los victimarios tiene secundaria completa, un $37,78 \%$ tiene estudios superiores y solo un $6,67 \%$ tiene educación primaria.

Responsable del Sostenimiento del Hogar, Año 2007-2008

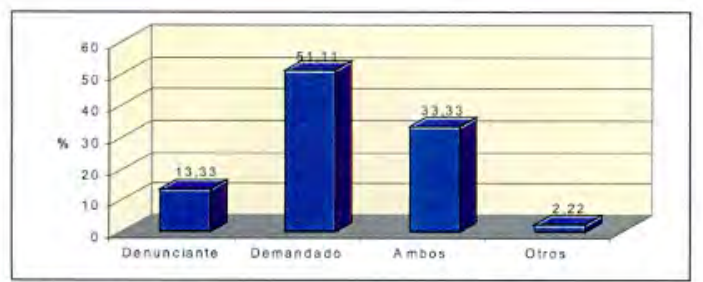

El 51,11\% de la muestra señala ser el demandado quien mantiene el hogar, un 33,33 ambas partes, un 13,33 por el denunciante, y un 2,22 señalan otros.

Tipo de Violencia Familiar Según el Informe Policial, Año 2007-2008

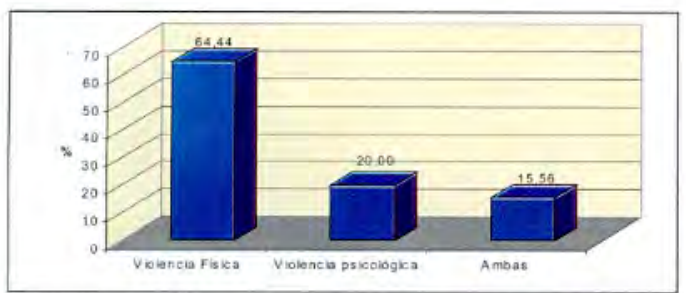

El 64,44\% de los casos corresponde al tipo de violencia física, un $20,00 \%$ violencia psicológica y un 15,56 ambas.

\section{DISCUSIÓN}

A la luz de los hallazgos encontrados del estudio de los expedientes de violencia familiar, se ha determinado que existen rasgos similares tanto en las víctimas como en los victimarios. Asi tenemos que la víctima generalmente es mujer $(97,78 \%)$, mientras que el $2,22 \%$ son varones, cuyas edades oscilan entre los 26 y 39 años de edad; asimismo, las victimas mayormente se dedican a las labores de casa y cuidado de los hijos, lo que las coloca en situación de desventaja frente al varón.

Por su parte el victimario, generalmente es un varón, con edades entre 26 a 39 años, pero a diferencia de la víctima, generalmente cuenta con estudios secundarios $y$ en algunos casos cuenta con estudios universitarios, lo que a su vez le permite contar con algún trabajo que le genere recursos económicos. por lo que consecuentemente se encuentra en mejor posición frente a la mujer.

Igualmente se ha verificado que existen caracteristicas familiares que rodean a la victima y victimario que hacen que este ciclo de violencia se repita. Asi tenemos que la violencia generalmente se da dentro del hogar, la mayor parte tiene una relación de convivencia, luego otro grupo son casados, y existen dos grupos menores conformados por ex cónyuges y ex convivientes; por tanto, la violencia se da dentro del domicilio que comparten.

Otro aspecto importante es que son los varones los que asumen generalmente el sostenimiento del hogar, y que las víctimas generalmente no sostienen el hogar, en algunos casos contribuyen al sostenimiento del hogar, y otros casos no trabajan, lo que definitivamente se refleja en mayor número de víctimas mujeres, y el mínimo número de casos de violencia sobre los varones.

En consecuencia tampoco será fácil el cese de la violencia tanto física como psicológica precisamente por esta situación de desigualdad económica en que se encuentran las mujeres frente a los varones, ocasionando que los actos de violencia se repitan de padres a hijos generando un ciclo vicioso que causa daño no solo a las víctimas directas sino también a los hijos y a la sociedad en general.

Precisamente por la situación vulnerable de la víctima, quien tiene serias dificultades para salir del ciclo de violencia por las características señaladas en los perfiles (grado de instrucción, no trabajar), es necesario realizar un trabajo de prevención con los probables victimarios que se podrían determinarsegún los perfiles hallados con la investigación.

\section{CONCLUSIONES}

En Cuanto al Perfil de la Víctima y del Victimario de Violencia Familiar:

1. Se ha demostrado que tienen ciertas características concurrentes: en muchos casos son convivientes, 
aunque también existe violencia entre cónyuges, ex cónyuges y ex convivientes; así mismo la víctima es casi en todos los casos mujeres, cuyas edades oscilan entre 26 y 39 años de edad, las que generalmente no tienen estudios superiores, teniendo únicamente estudios primarios y secundarios, y muchas de ellas no trabajan fuera de casa; es decir, se desempeñan en las labores domésticas y al cuidado de los hijos, por lo que se agrava la situación cuando son víctimas de violencia familiar, ya que no tienen recursos económicos para retirarse del hogar y mantener a sus hijos y a ella misma, por lo que muchas veces no denuncian o vuelven al hogar y se ven obligadas a soportar actos de violencia.

También tienen ciertas características que son concurrentes: como en el caso de la vetima son convivientes, pero en cuanto al sexo son generalmente varones los victimarios, cuyas edades oscilan entre 26 y 39 años de edad, muchos de ellos tienen educación secundaria y otro grupo tiene estudios superior, y casi todos ellos desempeñan algún oficio o profesión, que los coloca en situación de ventaja sobre las mujeres que son las víctimas de estos delitos, ya que los recursos económicos les permite tener cierto dominio sobre la víctima.

\section{En Cuanto a las Características Familiares de la Víctima} y Victimario en los Casos de Violencia Familiar

Se ha verificado que la violencia familiar se presenta en el hogar, ya sea en familias en situación

de convivencia, las que comparten el mismo domicilio, aunque también hay un grupo considerable constituido por personas que se encuentran en situación de ex cónyuges, ex convivientes o separados, siendo el varón el que asume el sostenimiento del hogar, mientras que la mujer (víctima) se dedica al cuidado de los hijos y a las labores propias del hogar.

\section{Respecto a la Magnitud de la Violencia Familiar en el Año 2008:}

Se concluye que la magnitud de la violencia familiar, valorada por el total de denuncias registradas en el año 2008 en el Centro de Emergencia Mujer en el departamento de Tacna, asciende a 729 casos, siendo el promedio de 2,8 casos por día, cifra que resulta superior al promedio nacional que fue de 2,1 casos por día.

\section{RECOMENDACIONES}

1. Creación de centros de acogida donde podrían permanecer por un tiempo razonable de acuerdo con su situación concreta. De esta forma se evitaría que la víctima vuelva a ser victimizada por el victimario, ya que de volver a casa es probable que la violencia sea mayor, ya que habría tal vez una dosis de venganza por la denuncia interpuesta.
2. Creación de centros de apoyo psicológico efectivos a fin de lograr un verdadero apoyo psicológico de las víctimas y un tratamiento psicológico del victimario, para así evitar que se repitan los actos de violencia, ya que lamentablemente las sentencias poco contribuyen al cese de violencia familiar y las pocas instituciones que actualmente prestan apoyo psicológico en la actualidad se encuentran sobrepasados en su capacidad de atención, por lo que en la actualidad no hay un efectivo tratamiento psicológico de las víctimas y victimarios.

3. Capacitación del personal que atiende los casos de violencia familiar, tanto a nivel policial como del Ministerio Público y el Poder Judicial y de las instituciones vinculadas como son el Instituto de Medicina Legal, Hospital, MIMDES, Centros de Protección de la Mujer, DEMUNAS, entre otras, ya que muchas veces las víctimas de violencia familiar nuevamente son víctimas de violencia por parte de algunas de las personas que atienden los casos de violencia familiar, ya que se niegan a recibir su denuncia o atender con la seriedad del caso, sobre todo en los casos de violencia psicológica, pues al no haber rasgos visibles de violencia es dificil su investigación y posterior sanción.

4. Establecimiento de lugares adecuados para la investigación de los casos de violencia familiar, tanto a nivel policial como en el Ministerio Público, Poder Judicial y otras instituciones, a fin de garantizar la privacidad de las víctimas y una atención adecuada.

5. Tomar medidas de prevención a fin de evitar casos de violencia familiar trabajando con los probables victimarios a partir de los perfiles de la víctima y victimario. Debiendo efectuarse campañas masivas y específicas de sensibilización con los varones sobre la no violencia contra la mujer, ya que estos son generalmente los que ejercen violencia física y psicológica contra las mujeres, lo que afecta también a los hijos y al entorno familiar $y$, finalmente, el desarrollo de la sociedad.

\section{REFERENCIAS BIBLIOGRÁFICAS}

RODRÍGUEZ CANALES, Fredy F. Tesis UNMSM, disponibleen sisbib. unmsm.edu.pe/BibVirtual Data/Tesis/Salud/RODRIGUEZ_C_F/CAPIT_pdf

Ministerio de la Mujer y Desarrollo Social, http// www.mimdes.gob.pe MERINO, Beatriz (2007) discurso de la doctora Beatriz Merino, Perú disponible en:http://www.elinformanteperu.com/opinion.php? idarticulos $=21625$

CHÁVEZ DE, LAZO ( 2006). Violencia familiar [ en linea]disponible en:http://www.monografias.com/ trabajos13/ mviolfam/mviolfam.shtml[ consulta : 2202.09].

PLÁCIDO V. Alex (2004) La Ley de Protección frente a la Violencia Familiar y su aplicación en la realidad social . Academia de la Magistratura. Disponible en: www.amag.edu.pe/files/violencia_familiar.ppt 